\title{
Sea Level Rise in the CESM Large Ensemble: The Role of Individual Climate Forcings and Consequences for the Coming Decades
}

\author{
JOHN T. FASULLO \\ National Center for Atmospheric Research, and University of Colorado Boulder, Boulder, Colorado \\ PETER R. GENT \\ National Center for Atmospheric Research, Boulder, Colorado \\ R. STEVEN NEREM \\ University of Colorado Boulder, Boulder, Colorado
}

(Manuscript received 29 December 2019, in final form 2 April 2020)

\begin{abstract}
The emergence of a spatial pattern in the externally forced response (FR) of dynamic sea level (DSL) during the altimeter era has recently been demonstrated using climate models but our understanding of its initial emergence, drivers, and implications for the future is poor. Here the anthropogenic forcings of the DSL pattern are explored using the Community Earth System Model Large Ensemble (CESM-LE) and SingleForcing Large Ensemble, a newly available set of simulations where values of individual forcing agents remain fixed at 1920 levels, allowing for an estimation of their effects. Statistically significant contributions to the DSL FR are identified for greenhouse gases (GHGs) and industrial aerosols (AERs), with particularly strong contributions resulting from AERs in the mid-twentieth century and GHGs in the late twentieth and twentyfirst century. Secondary, but important, contributions are identified for biomass burning aerosols in the equatorial Atlantic Ocean in the mid-twentieth century, and for stratospheric ozone in the Southern Ocean during the late twentieth century. Key to understanding regional DSL patterns are ocean heat content and salinity anomalies, which are driven by surface heat and freshwater fluxes, ocean dynamics, and the spatial structure of seawater thermal expansivity. Potential implications for the interpretation of DSL during the satellite era and the longer records from tide gauges are suggested as a topic for future research.
\end{abstract}

\section{Introduction}

The altimeter record of sea level has now reached a major milestone at over 27 years in length. These measurements have been collected by the TOPEX/Poseidon and Jason (Jason-1, Jason-2, and Jason-3) series of satellites and are synthesized into 10-day gridded fields by several data centers around the globe, revealing a complex pattern of trends (Aparna et al. 2012; Bromirski et al. 2011; Carson et al. 2016; Calafat et al. 2013; Hamlington et al. 2019). The distribution, magnitude, and attribution of these patterns is an issue of significant socioeconomic importance (Hauer et al. 2016; Neumann et al. 2015; Moftakhari et al. 2015). Elevated rates of rise enhance the impacts of rising sea levels, which include saltwater

Corresponding author: J. Fasullo, fasullo@ucar.edu intrusion, erosion, storm surges, and tidal flooding, and some of the highest rates of rise have occurred in the most vulnerable regions (Peyser et al. 2016; Fasullo and Nerem 2018; Storlazzi et al. 2018). Conversely, regionally reduced rates of rise, where persistent, will extend adaptation time scales and reduce associated impacts.

Regional sea level changes are driven by changes in winds, currents, ocean heat content, and salinity. They are also influenced by the thermal expansion coefficient of seawater, which varies strongly as a function of location and depth. Together, these effects result in a complex pattern of sea level change under climate change (Fasullo and Nerem 2018). Industrial and biomass aerosols and greenhouse gases (GHGs) are major forcings in determining where, and how much, heat and freshwater enters the oceans, and how winds and currents change. Given that these forcing agents have 
varied substantially though the twentieth century, is there a need to account for the associated patterns in reconstructing global fields from sparsely distributed tide gauge data? Typically, such patterns have been assumed to be small, but are they?

Although patterns of sea level rise are known to be influenced by internal modes of climate variability, including the North Atlantic Oscillation (Kenigson et al. 2018), ENSO, (Nerem et al. 1999; Chambers et al. 2002; Dieng et al. 2014; Han et al. 2017) and the Pacific decadal oscillation (Cummins et al. 2005; Zhang and Church 2012; Hamlington et al. 2014, 2016, 2019), more recently it has been shown using climate models that the underlying pattern driven by climate forcings has been a significant contributor to altimeter-era trends, with an influence that will increase in the coming decades (Bilbao et al. 2015; Fasullo and Nerem 2018). This finding has far reaching implications as it suggests that recently observed regional contrasts in rate are not solely the result of internal variations, which would average to zero in the long term, but instead are part of a sustained pattern that will contribute to persistent impacts as both the global-mean rise and its regional deviations evolve and accelerate (Nerem et al. 2018). The patterns are also significant in that they have the ability to alias the understanding of rise over the tide gauge era if not correctly accounted for.

A better understanding of the drivers of the patterns offers a path forward for anticipating and estimating the magnitude of near-future rise and impacts. However, a key uncertainty in predicting the evolution is the uncertainty in future climate forcings (O'Neill et al. 2014). Historically, developed economies have enacted policy that limits industrial and motor vehicle aerosol (AER) emissions, such as the Clean Air Act of 1963 in the United States and the Air Quality Framework Directive in Europe (Lamarque et al. 2010; Gillett and Von Salzen 2013). It is broadly anticipated that, in time, similarly stringent actions will be undertaken in the regions of current strong emissions, particularly in Southeast Asia where emissions constitute a large fraction of the global total (Rogelj et al. 2014; O'Neill et al. 2014). As these policy actions are considered, is there an expectation of consequences for regional rates of sea level rise?

The roles of other climate forcings also remain to be understood. Elevated concentrations of greenhouse gases are associated with warming during the altimeter era (Jones et al. 2003) and its associated spatial patterns (Stott et al. 2010). What role have GHGs played in altimeter-era sea level trend patterns? Are the patterns consistent over time, and therefore well characterized by pattern scaling, or do they evolve? Are the main features of the altimeter era consistent with GHG influences and therefore be expected to continue into the future as emissions continue? Or, in either the historical era or coming decades, is there an important role for other climate forcings, including biomass burning emissions, stratospheric ozone reductions, or land-use and landcover (LULC) changes (Lamarque et al. 2011)?

In this work we use a novel ensemble of climate model simulations to explore these and related questions. In the ensemble, individual forcing agents are held fixed at 1920 levels while concentrations and burdens of other climate forcing agents are allowed to vary in time. The simulations begin in 1920 and vary in their duration, extending to 2080 for the strongest global climate forcings (GHGs, AERs). The modeling configuration used is identical to that of a recent single-model ensemble, the Community Earth System Model version 1 (CESM; Hurrell et al. 2013) Large Ensemble (LE; Kay et al. 2015), in which an identical set of complete time-varying forcings is prescribed. The ensembles and their designs are described in greater detail in section 2, while zonal-mean summaries of the forced responses are examined in section 3. Based on these summaries, three intervals are identified as exhibiting approximately uniform responses: $1950-93$, referred to as the pre-altimeter era; 1993-2020, the altimeter era; and 2020-50, the post-altimeter era. Structures of trends and associated mechanisms are explored in sections 4,5 , and 6 , respectively. The role of salinity changes is addressed in section 7 , while interbasin contrasts and mechanisms are explored further in section 8. A discussion of the results, their broader significance for our understanding of sea level, and associated limitations in considering only a single climate model and the concluding remarks are presented in section 9 .

\section{Methods}

Model simulations considered in this work are generated using the CESM (Hurrell et al. 2013). The CESM-LE ocean component is the Parallel Ocean Program version 2 (POP2; Smith et al. 2010). The model implements the Bousinnesq approximation, in which density variations are only considered where multiplied by the acceleration of gravity in the equations of motion. The model's formulation for dynamic sea level (DSL) allows for regional fluctuations arising from both dynamic and steric effects while holding the global ocean volume (and thus the global-mean sea level) fixed. On long time scales, such as those considered in this work, variations in DSL are generally dictated by steric effects (Fasullo and Gent 2017; Fasullo and Nerem 2018) although some regional exceptions may exist.

The CESM ensembles used here are the 40-member CESM Large Ensemble (CESM-LE; Kay et al. 2015) and Single-Forcing Large Ensemble (CESM-SF; Deser et al. 2020). The simulations are conducted with identical CESM configurations, with the sole distinction relating to the implementations of external climate forcings. The CESM-LE employs a full set of forcing concentrations including GHGs, volcanic aerosols, industrial 
AERs, biomass burning aerosols (BMBs), and stratospheric and tropospheric ozone, in addition to changes in (LULC) attributes. In contrast, the CESM-SF simulations are performed where an individual forcing is held fixed in time. For GHG and AER simulations, 20 members spanning 1920-2080 exist for which concentrations are fixed at 1920 levels. For BMB and LULC simulations, conditions are fixed at 1920 values and simulations span 1920-2029 for 15 and 5 members, respectively. As the CESM-SF does not include some natural forcings, such as solar variability and volcanic eruptions, one does not expect an accounting of the full variability in the CESM-LE. However, on the temporal and spatial scales considered here we do find mostly close agreement between the sum of the effects of individual forcing agents considered in the CESMSF with the fully forced response, with some exceptions as discussed below.

As contributions from internal variability are generally well characterized as Gaussian noise (Kay et al. 2015; Deser et al. 2020), the forced response in each ensemble can be estimated from the ensemble mean. The impact of individual forcings can be estimated by differencing the CESM-SF simulations, in which they are held constant, from the 40member CESM-LE. This difference provides an estimate of the climate response with an uncertainty that is proportional to $\left\{\left[1 /(40-1)^{1 / 2}\right]^{2}+\left[1 /(N-1)^{1 / 2}\right]^{2}\right\}^{1 / 2}$, where $N$ is the number of SF ensemble members. Drift is accounted for in the CESM-LE by differencing the ensemble mean with its accompanying preindustrial control run, smoothed with a 70 -yr running mean to remove transient internal variability. Drift in the CESM-SF is implicitly accounted for by differencing with the CESM-LE, as the ensembles are initialized using the same base states and microperturbation approach, as described in Kay et al. (2015), and thus contain the same drift. Simulations in which ozone (OZO) has been held fixed at 1955 levels, not formally included in the CESM-SF, are also used in this work (Previdi and Polvani 2014). These are also initialized from CESM-LE members and therefore share a common underlying drift. The forcings held fixed in the CESM-SF do not span the entire set of climate forcings, most notably omitting solar and volcanic effects, and thus (as will be seen) a complete accounting for responses in the CESM-LE is neither expected nor simulated.

To provide context for the structure of trends during the altimeter era referenced in the following sections, Fig. 1 shows the updated pattern of trends in the altimeter record (Fasullo and Nerem 2018), where the global mean has been removed, along with the associated forced response in the CESM-LE, where the global mean is zero by design. Noteworthy features common to both patterns include pervasive negative trends south of about $50^{\circ} \mathrm{S}$, with positive trends to their north, negative

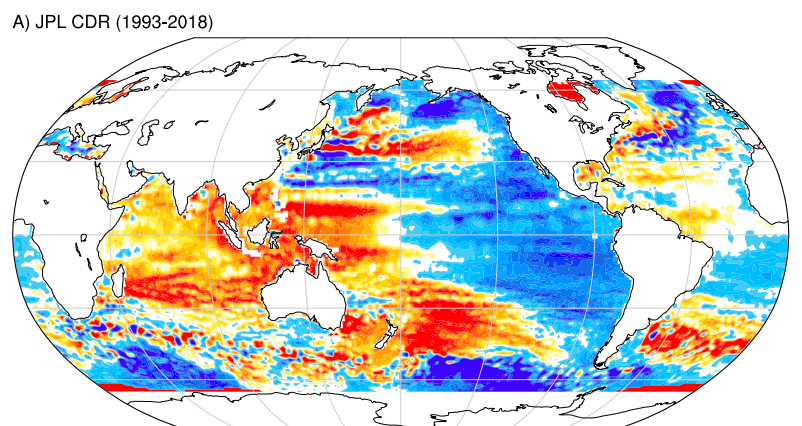

B) CESM-LE FR (1993-2018)

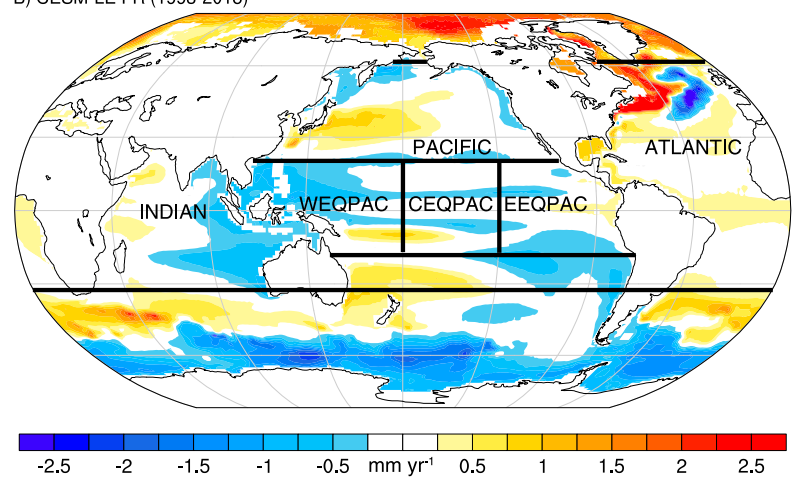

FIG. 1. Map of regional altimeter-era trends (global mean removed) from (a) JPL's Climate Data Record (CDR) and (b) the forced response of DSL from the CESM-LE. Also shown are regions referenced later in text for the Indian, Pacific, and Atlantic Ocean basins, and for the western (WEQPAC), central (CEQPAC), and eastern (EEQPAC) equatorial Pacific Ocean.

trends in the eastern Pacific Ocean, and positive trends in the tropical Atlantic Ocean and in the western Northern Hemisphere boundary currents and their extensions, accompanied by neighboring negative trends. There are also significant differences in both the smaller amplitude of the LE forced response and in regional patterns especially in the tropical Pacific and Indian Oceans. These differences are likely caused by noise arising from internal modes of variability in both the real climate system (see Hamlington et al. 2019, their Fig. 4c) and the model (Fasullo and Nerem 2016), and by biases in the CESM-LE simulations, which arise from model error, error in imposed forcings, and associated interactions between forcings and physical fields (e.g., AERs and clouds). As biases in the CESM response to forcing are likely to exist, future work examining the robustness of the results herein across models is planned.

\section{Zonal-mean forced responses}

The CESM-LE FR for ocean fields, particularly those that implicitly integrate through the depth of the ocean column, is highly variable in space and time. In part, the time-evolving structure is associated with the long time scales on which 

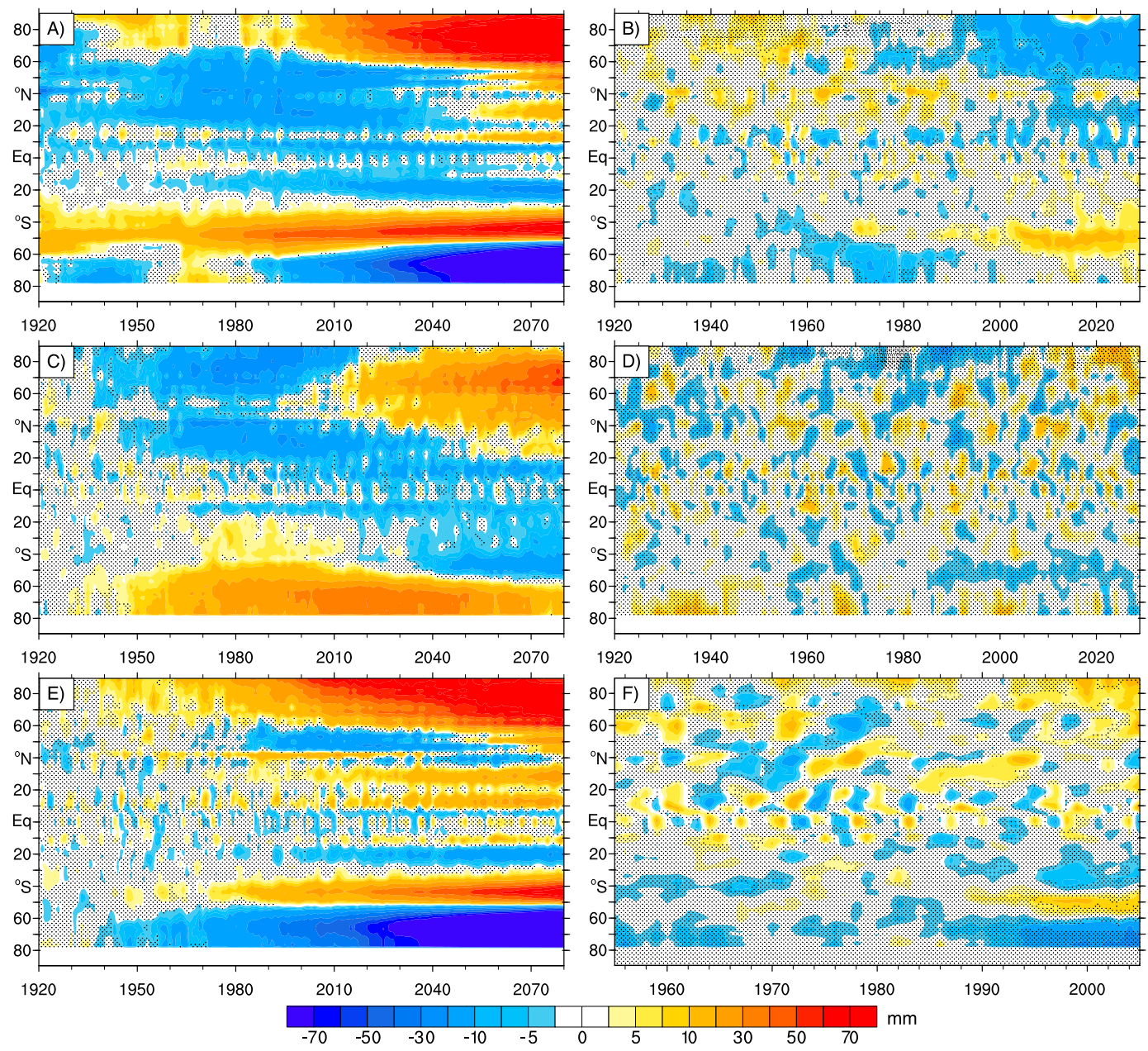

FIG. 2. Zonal-mean evolution of the ensemble means from (a) the fully forced CESM-LE and individual contributions from (b) biomass burning, (c) industrial aerosols, (d) land use and land cover, (e) greenhouse gases, and (f) ozone. Time periods in (b), (d), and (f) are limited by the duration of the simulations. Fields are stippled/white where the means are less than twice the ensemble standard errors, which are larger in (b), (d), and (f) due to fewer ensemble members.

anomalies enter the ocean and are advected, subducted, and mixed through its depth (see sections 4-7). As will be shown (section 8), the space-time structure of climate forcings is also a driver of complexity. A useful approach for diagnosing forced changes in the midst of this complexity is through examination of the zonal-mean structure of the forced responses. In Fig. 2, this structure is shown using departures from the PI-control run of the CESM-LE (Fig. 2a), and the CESM-LE difference with CESM-SF ensemble means for BMB, AER, LULC, GHG, and OZO members (Figs. 2b-f, respectively), with insignificant differences (less than twice the ensemble standard errors) indicated by stippling. The CESM-LE FR is characterized by negative dynamic sea level anomalies in the Northern Hemisphere $(\mathrm{NH})$ during much of the twentieth century, which begin at the ensemble initialization in 1920 and follow a series of strong volcanic eruptions.
The negative anomalies intensify in the mid-twentieth century, accompanying an intensification of positive anomalies in the SH. Toward the end of the twentieth century, negative NH anomalies begin to weaken while a Southern Hemisphere (SH) dipole of anomalies emerges and intensifies and positive anomalies emerge in the Arctic, trends that continue well into the twenty-first century. Anomalies driven by BMBs are generally not significant, with the exception of small negative anomalies in the Antarctic in the late twentieth century and opposing anomalies in the Arctic (negative) and Antarctic (positive) in the early twenty-first century. Strong responses to AERs are evident and begin in about 1940, with pervasive negative anomalies in the $\mathrm{NH}$ and generally positive anomalies in the $\mathrm{SH}$ (note that the global mean in DSL is zero by design). In the early twenty-first century, the $\mathrm{NH}$ 

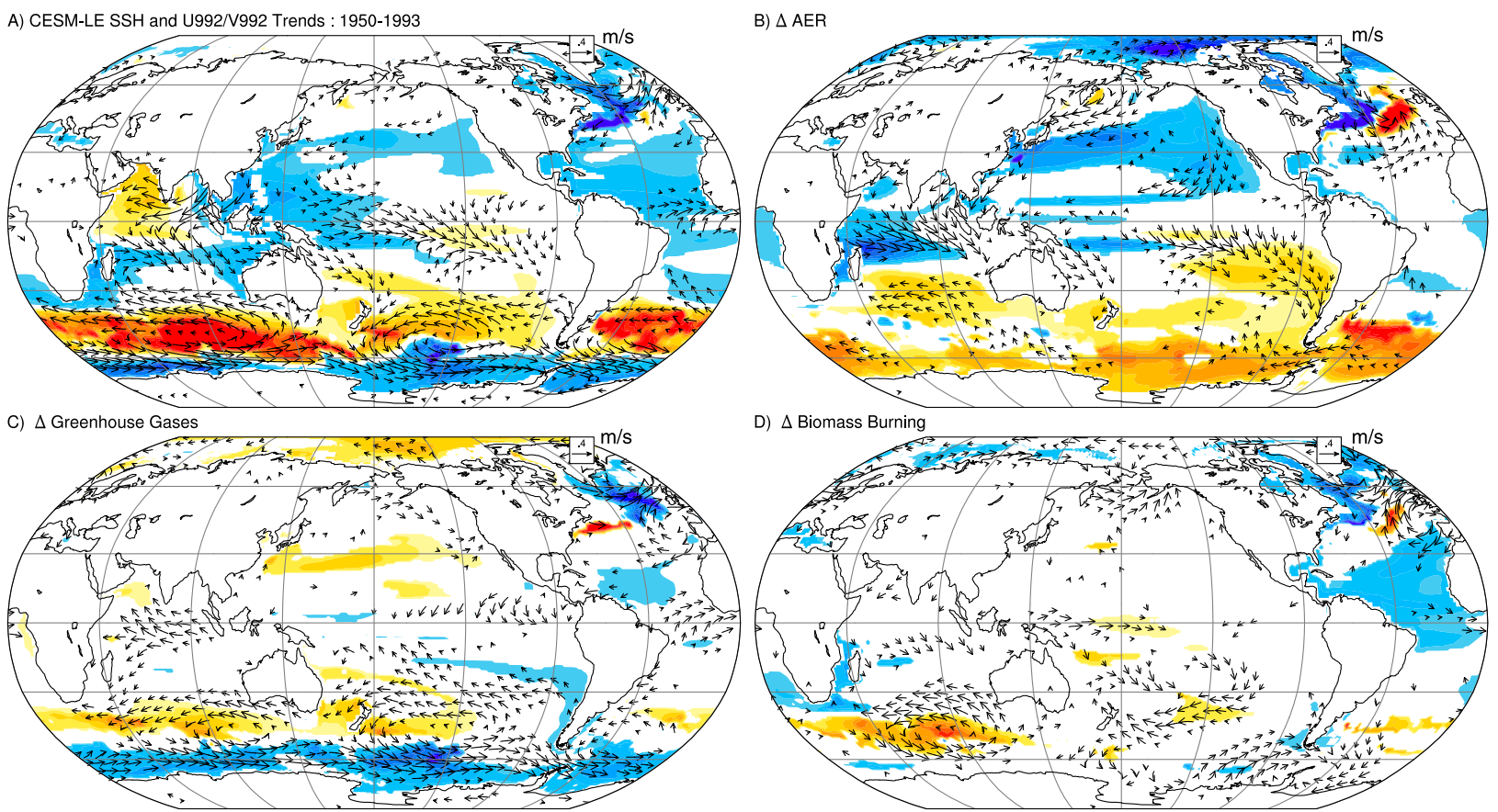

D) $\Delta$ Biomass Burning

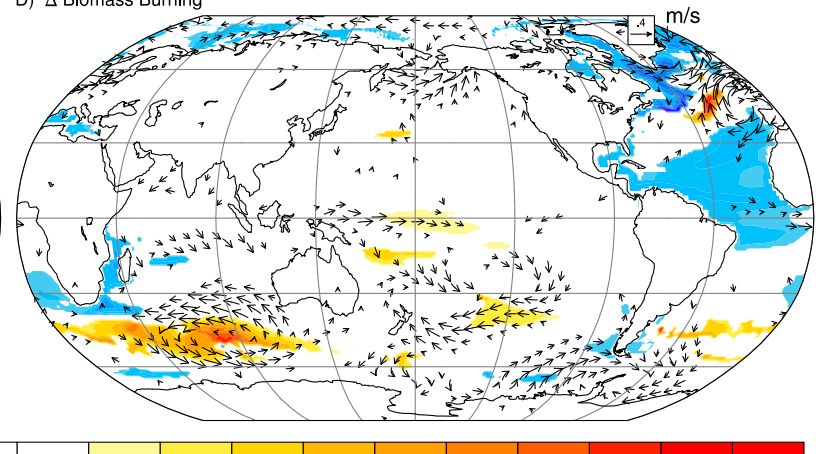

$\begin{array}{lllllllllllllllllllll}-50 & -45 & -40 & -35 & -30 & -25 & -20 & -15 & -10 & -5 & \mathrm{~mm} & 5 & 10 & 15 & 20 & 25 & 30 & 35 & 40 & 45 & 50\end{array}$

FIG. 3. (a) Ensemble-mean trends in DSL (mm) and lower-tropospheric winds (vectors; $\mathrm{m} \mathrm{s}^{-1}$ ) from 1950 to 1993 for the CESM-LE, and estimated contributions from (b) industrial aerosols, (c) greenhouse gases, and (d) biomass burning. All filled contours exceed twice the ensemble standard error.

anomalies dissipate and transition to positive north of $30^{\circ} \mathrm{N}$, while negative anomalies emerge in the $\mathrm{SH}$ and strengthen, except south of $60^{\circ} \mathrm{S}$ where positive anomalies persist through 2080. Anomalies driven by LULC (Fig. 2d) are generally insignificant, with less than $5 \%$ of the domain exhibiting significance. In contrast, the response to GHGs (Fig. 2e) is both strong and pervasive, with forced responses emerging near 1940 and characterized initially by positive values in the Arctic and negative values in the Antarctic. By the late twentieth and into the twenty-first century, the spatial pattern becomes considerably more complex, with maxima emerging and intensifying near $40^{\circ}$ in each hemisphere and transient negative anomalies existing near $45^{\circ} \mathrm{N}$, on the equator, and at $30^{\circ} \mathrm{S}$ at most times. Anomalies driven by OZO are small generally, with the exception of a dipole of anomalies in the SH that emerges in the 1990s and is centered south of that driven by GHGs, amplifying negative values around the Antarctic coast and associated with changes in nearsurface winds and ocean currents (Armour et al. 2016).

An interesting question is whether the sum of the sea level signals in all the individual forcing runs add up linearly to the signal in the fully forced run. This question cannot be answered completely because there are no single forcing runs for variations in solar output and volcanic effects, which are varied in the fully forced run. However, when the signals from all the individual forcing runs made are added together, they do not add up to the fully forced run in two regions. The first is in the $\mathrm{SH}$ between $50^{\circ}$ and $70^{\circ} \mathrm{S}$, where there are opposing signals due to GHGs, aerosols, and ozone associated with changes in wind stress, so it is not surprising there are some nonlinear interactions in this region. The second location is in the Arctic, which is a little more surprising. However, Deng et al. (2019) and Zhao et al. (2019) have shown that there is a nonlinear interaction between GHG and aerosol forcings in their seasonal effects on the sea ice and snow cover distributions.

\section{Spatial structure and mechanisms: 1950-93}

Zonal-mean structures are useful in identifying broad periods of coherent change, but they are limited in their ability to characterize the full structure of trends observed during the altimeter era. Ultimately, the understanding and projection of impacts also relies on details in the spatial structure of trends that are not captured in zonal averages. Therefore, maps of trend spatial structure for DSL and winds in the lowest tropospheric model level over 1950-93 are shown in Fig. 3 for the CESM-LE (Fig. 3a) and the dominant forcings identified in Fig. 2 for this period, AERs, GHGs, and BMBs (Figs. 3b-d, respectively). The CESM-LE FR is characterized by pervasive negative trends across the $\mathrm{NH}$, and a westerly wind trend on the equator, suggestive of a weakening Walker circulation. DSL anomalies 

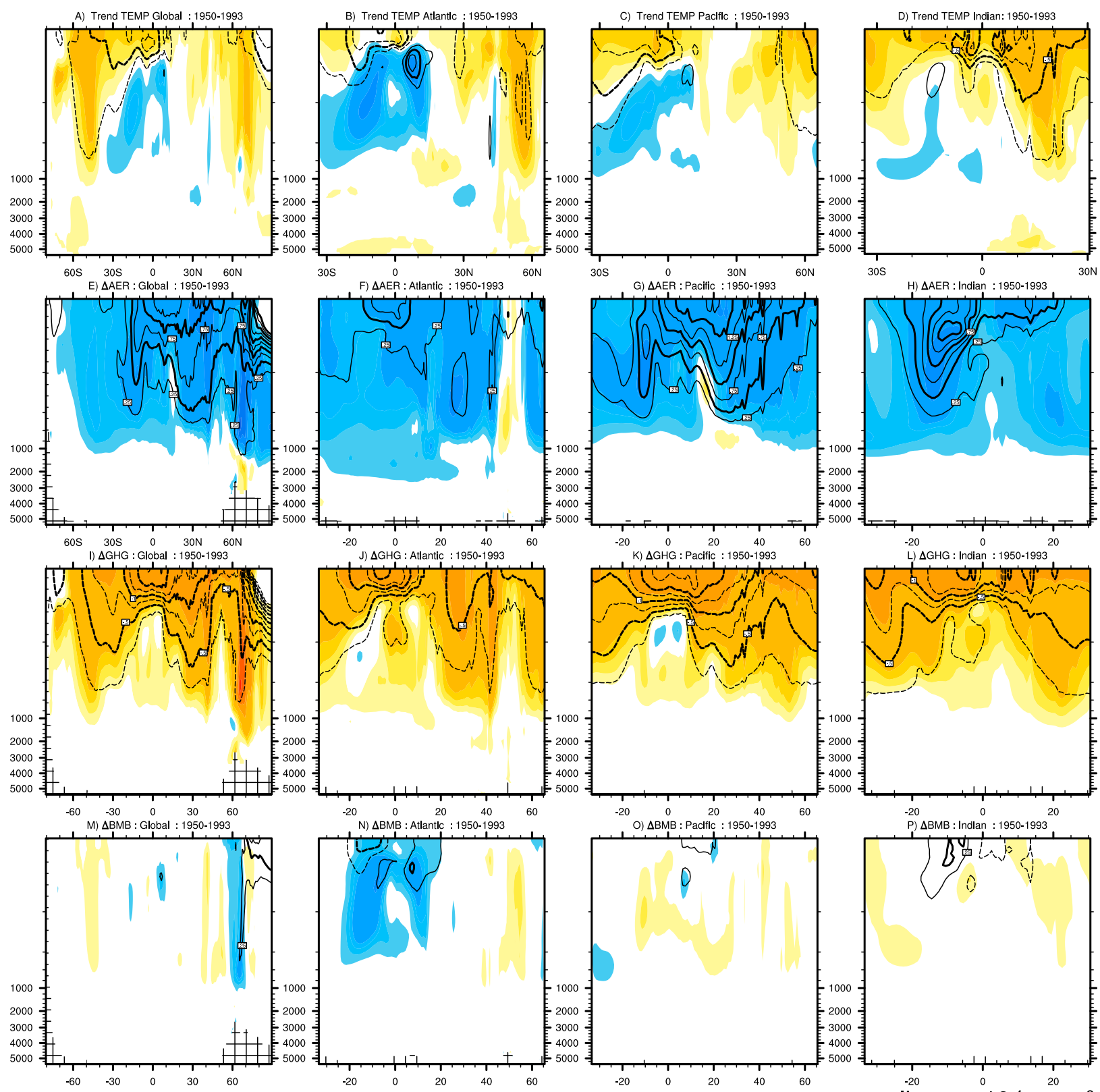

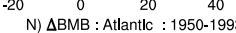

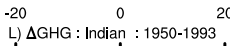

L) $\Delta \mathrm{GHG}:$ Indian : 1950-1993

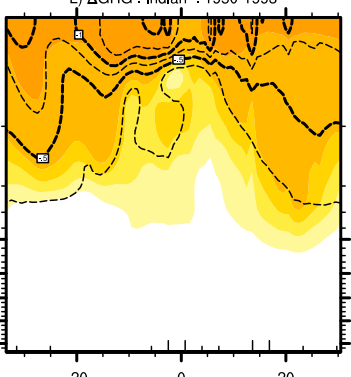

P) $\triangle B M B$ : Indian : 1950-1993

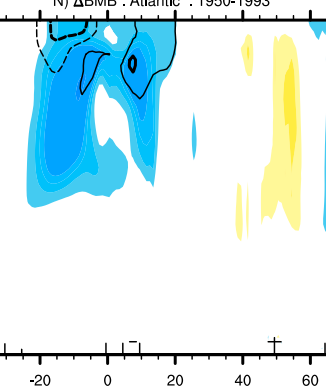

-20 20 (O) $20 \quad 40$

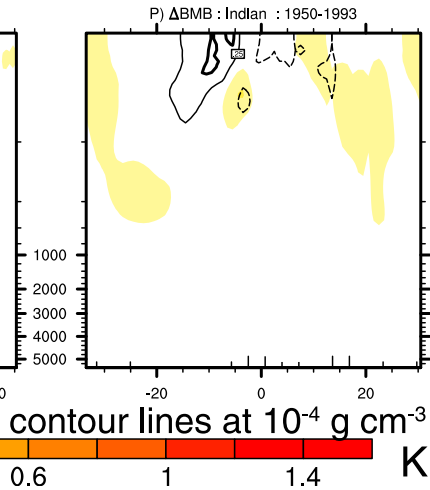

$-1.4$

$-1$

$-0.6$

$-0.2$

$-0.1$

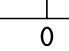

0.1 0.2

1.4

FIG. 4. The vertical structure of trends in ocean temperature (colors; K) and potential density (lines; $10^{-4} \mathrm{~g} \mathrm{~cm}^{-3}$ at intervals of 0.25 ) from 1950 to 1993 for the (a),(e),(i),(m) global ocean and the (b),(f),(j),(n) Atlantic, (c),(g),(k),(o) Pacific, and (d),(h),(l),(p) Indian Ocean basins. Contributions considered include (a)-(d) all forcings, (e)-(h) aerosols, (i)-(l) greenhouse gases, and (m)-(p) biomass aerosols. All filled contours exceed twice the ensemble standard error. Note that contrasting latitudinal ranges exist across basins.

in the $\mathrm{SH}$ are characterized mainly by a dipole centered about $60^{\circ} \mathrm{S}$, and an accompanying dipole in zonal wind anomalies that contributes to Ekman drift away from Antarctica. A contribution to hemispherically contrasting DSL trends due to AERs (Fig. 3b) is evident, with accompanying easterly anomalies south of the equator in the Indian and Pacific Ocean basins and a complex pattern of change in the North Atlantic.
Contrasting starkly is the pattern of trends driven by GHGs, which include a DSL-wind dipole in the Southern Ocean that resembles the CESM-LE and modest changes elsewhere except in the North Atlantic. Responses to BMBs (Fig. 3d) involve a complex spatial pattern over the North Atlantic with a weak negative trend in the subtropics and a band of positive anomalies along $45^{\circ} \mathrm{S}$, which is particularly strong in the Indian Ocean. 

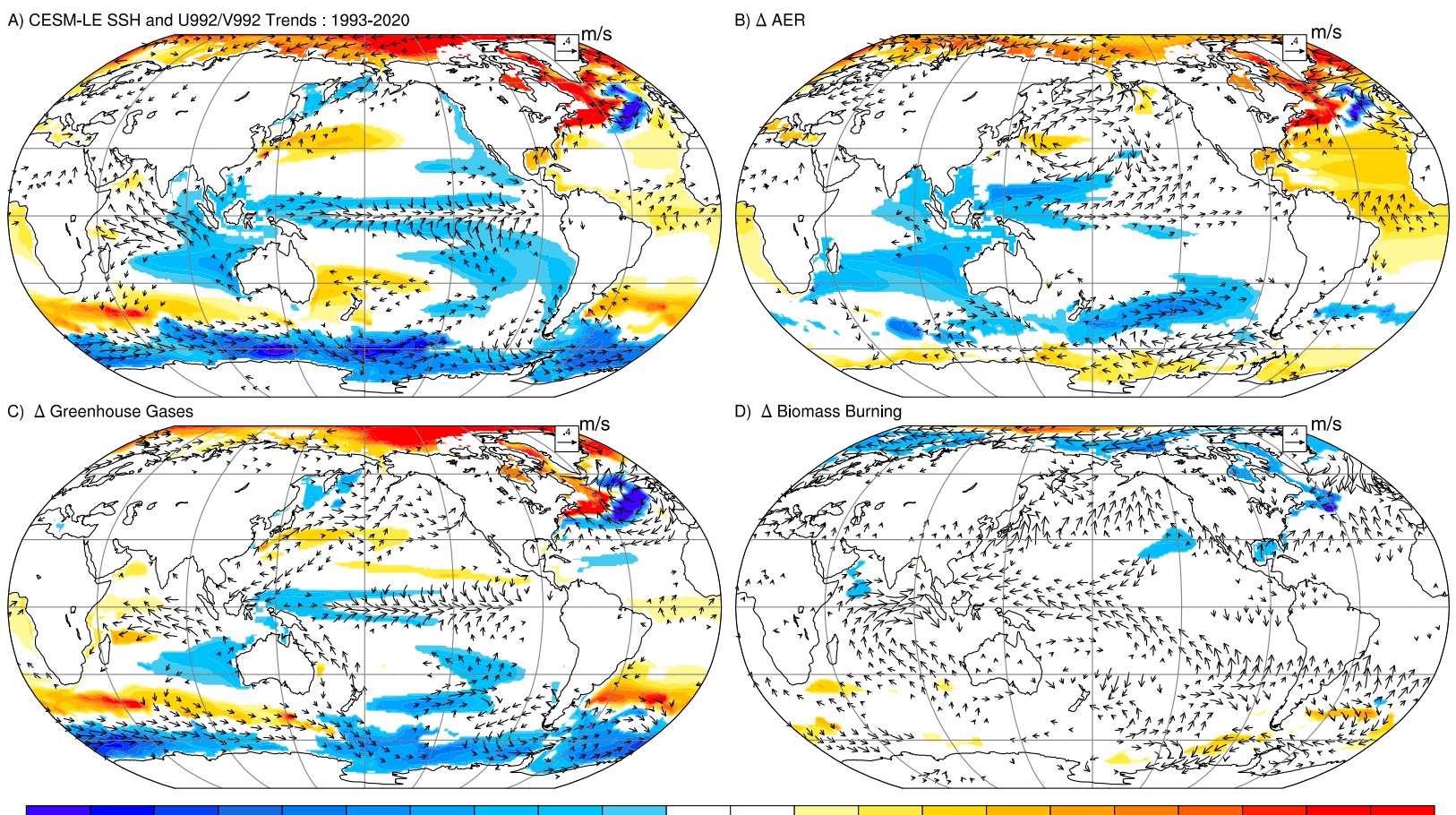

$$
\begin{array}{lllllllllllllllllllll}
-50 & -45 & -40 & -35 & -30 & -25 & -20 & -15 & -10 & -5 & \mathrm{~mm} & 5 & 10 & 15 & 20 & 25 & 30 & 35 & 40 & 45 & 50
\end{array}
$$

FIG. 5. As in Fig. 3, but for 1993-2020.

Trends in the vertical ocean structure in temperature $(T)$ and potential density (PD), which is inversely proportional to changes in DSL, over 1950-93 are shown in Fig. 4. Note that while DSL is constrained to be zero in the global mean, $T$ and PD are not. While a general warming of the surface ocean is apparent in all basins (Figs. 4a-d), considerable structure in both latitude and depth is apparent. Cooling trends are pervasive for AERs and are strongest in the $\mathrm{NH}$ (Figs. 4e-h) with PD increases that are particularly strong and widespread in the Pacific Ocean. Opposing these trends are those driven by GHGs (Figs. 4i-1), which, although comparable in magnitude, do not penetrate as deeply as those driven by AERs, likely due to the opposite effects each have on buoyancy, vertical stability, mixing, and overturning. An important influence of BMBs is also evident in the Atlantic Ocean, where cooling trends penetrate to depth and increase the $\mathrm{PD}$ in the $\mathrm{NH}$ while reducing it in the SH (likely as a result of changes in salinity via rainfall and perhaps advection).

\section{Altimeter-era spatial structures and mechanisms}

Contrasting starkly with simulated trends from 1950-93 are CESM-LE trends during the altimeter era (Fig. 5a), which are characterized by an intensified Southern Ocean dipole, basinwide positive trends in the Atlantic Ocean, and negative trends in the low-latitude tropical and Indian Oceans. A reversal of the influence of AERs (Fig. 5b) is notable in many regions, with strong positive trends extending across the Atlantic Ocean, with the exception of a dipole in the North Atlantic, and pervasive negative trends in the $\mathrm{SH}$, with weak but extensive positive trends near Antarctica and in the Arctic. The reversal likely arises in part from gradual changes in aerosol concentrations following enacted policies, such as for example the Clean Air Act of 1963 in the United States and the Clean Air Act 1956 in the United Kingdom (e.g., Granier et al. 2011; O'Neill et al. 2014). The response to GHGs (Fig. 5c) is also spatially complex and is characterized by a negative SO trend dipole (which is also augmented by OZO; Fig. 2f), negative trends in the tropical and South Pacific Ocean, a dipole in the North Atlantic, and strong positive trends in the Arctic. In contrast to the pre-altimeter era, BMBs (Fig. 5d) has little discernable impact on DSL trends during the altimeter era, with the possible exception of negative trends associated with cooling in the Arctic.

The vertical structure of $T$ and PD trends simulated for the altimeter era is shown in Fig. 6. For the CESM-LE (Fig. 6a), warming and reduced PD is broadly simulated for the upper ocean in each ocean basin, with cool anomalies mainly confined to the tropical Pacific Ocean near $200 \mathrm{~m}$ just off the equator that arise from shifts in surface winds that enhance surface westerlies and reduce upwelling 

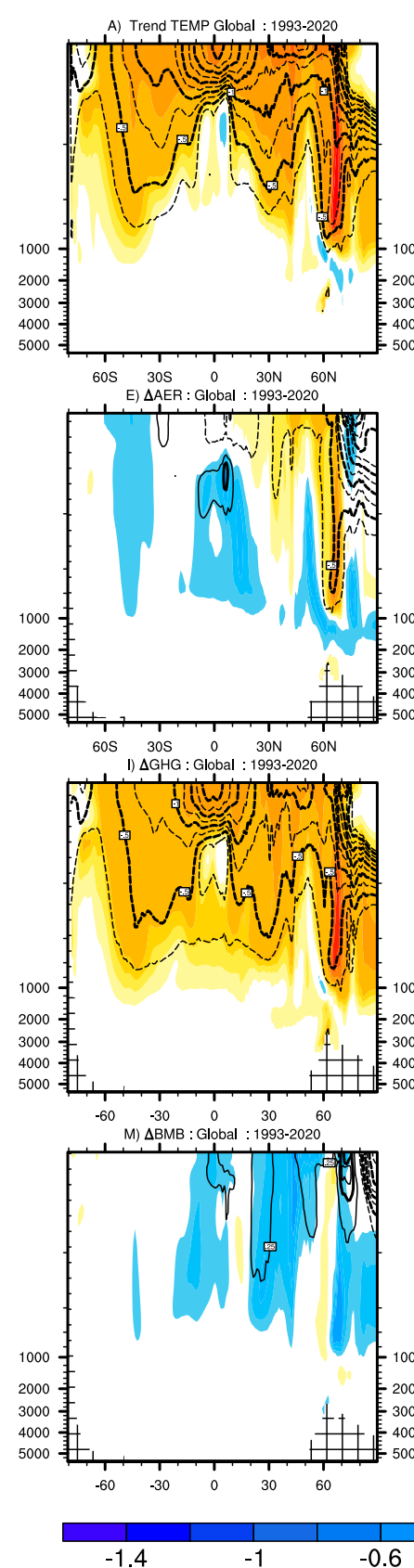
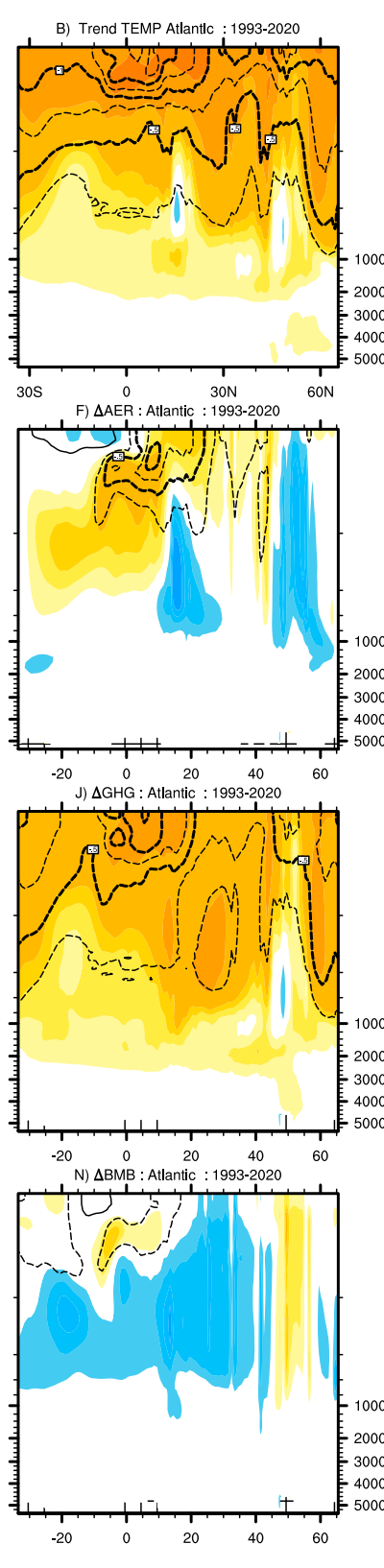
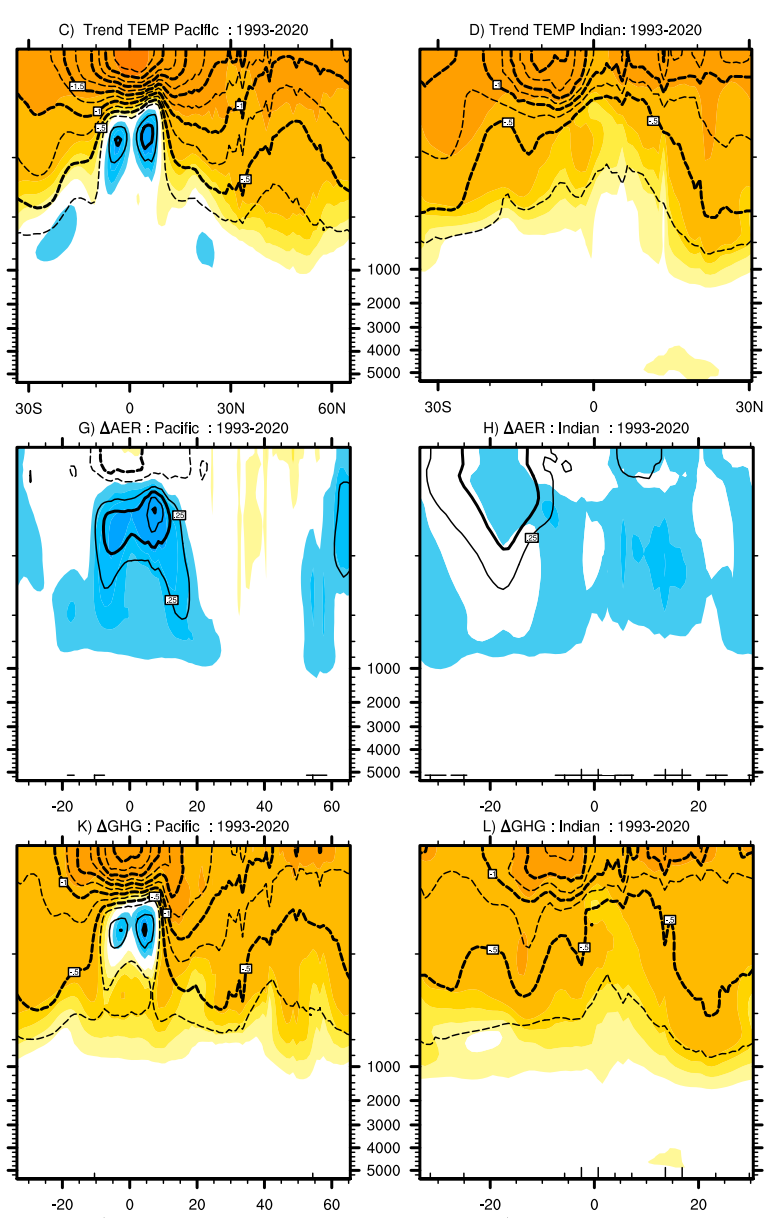

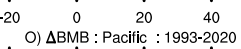
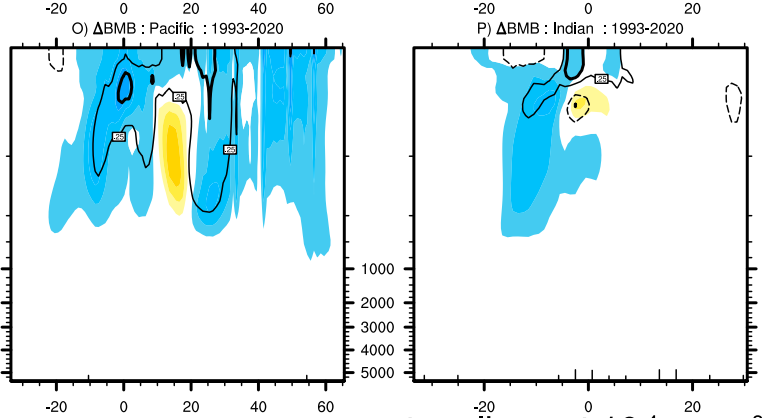

contour lines at $10^{-4} \mathrm{~g} \mathrm{~cm}^{-20}$

FIG. 6. As in Fig. 4, but for 1993-2020.

on the equator and downwelling just off the equator in the western Pacific Ocean. Changes in AERs drive a spatially complex pattern of change, with pervasive warming and PD reduction in the Atlantic Ocean, cooling and PD increases at depth in the equatorial Pacific Ocean, and weak but extensive cooling in the Indian Ocean. AER-driven trends are small generally relative to changes driven by GHGs, which are characterized by strong warming and PD reductions in all ocean basins, with the continued exception of a small area of cooling near $200 \mathrm{~m}$ in the tropical Pacific Ocean. The response to BMBs continues to be characterized by cooling and positive PD trends generally, with the strongest effect in the Pacific and occurring mainly below $100 \mathrm{~m}$ in the Atlantic and only in the deep tropics of the Indian Ocean.

\section{Spatial structures and mechanisms projected for the coming decades}

The projected forced response in the CESM-LE from 2020 to 2050 (Fig. 7a) in many ways resembles that 
A) CESM-LE SSH and U992/V992 Trends : 2020-2050
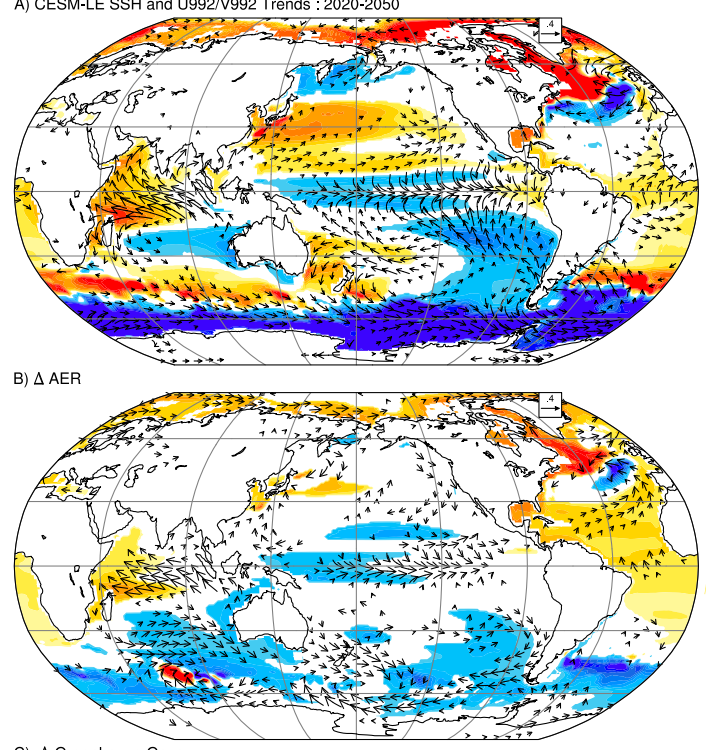

C) $\Delta$ Greenhouse Geses

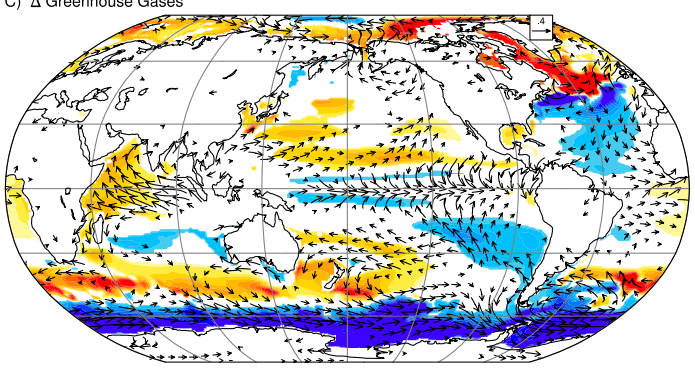

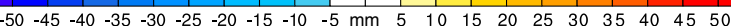

FIG. 7. Ensemble-mean trends in DSL (contours; $\mathrm{mm}$ ) and surface winds (vectors; $\mathrm{m} \mathrm{s}^{-1}$ ) from 2020-50 due to (a) all forcings, (b) aerosols, and (c) GHGs. All filled contours exceed twice the ensemble standard error

during the altimeter era, with a strong dipole of DSL trends in the Southern Ocean, negative DSL trends in the tropical and southeastern Pacific Ocean and trends in winds suggestive of a weakened Walker circulation, and positive DSL trends across much of the Atlantic Ocean and NH generally. The response to AERs (Fig. 7b) contributes positively to many of the trends in the CESMLE, with a continued broad-scale pattern of DSL increase in the Atlantic and western Indian Oceans, and pervasive negative anomalies across the western equatorial Pacific and Southern Ocean. The response to GHGs (Fig. 7c) also contributes strongly to the net DSL trend, driving the Southern Ocean dipole and contributing to positive trends in the western Indian and North Pacific Oceans. Interestingly, GHGs drive negative DSL trends in the tropical and subtropical North Atlantic, offsetting some of the effects of AERs, and strong elevated rates of rise extending from the subpolar North Atlantic into the Arctic. As the BMB simulations end in 2029 in the CESMSF, their influence through 2050 cannot be characterized.
The vertical structure of trends of $T$ and PD from 2020 to 2050 in the CESM-LE (Figs. 8a-d) is similar to that for 1993-2020 but the warming and reduction of PD strongly intensified and deepened to extend to $2 \mathrm{~km}$ in most basins. Reduced aerosol burdens lead to an overall reduction in albedo and an increase in absorbed solar radiation. In AERs (Figs. 8e-h), this effect contributes to warming at most levels in the global mean and pervasive warming across ocean basins, as aerosol concentrations continue to decline across all ocean basins, with the exception of the subpolar North Atlantic due to reduced mixing to depth of warm upper-ocean waters. The response to GHGs (Figs. 8i-1) is strong warming and reduction of PD virtually everywhere, so it dominates the full CESM-LE response and is the primary driver of pervasive warming and negative PD trends in the future.

Figure $8 \mathrm{~b}$ shows that the potential density is only increasing slightly in the North Atlantic between $20^{\circ}$ and $45^{\circ} \mathrm{N}$, whereas it is increasing much more strongly elsewhere in the Atlantic. This is due to the GHG signal shown in Fig. 8j. This results in the DSL signal in Fig. 7c, which recall only shows the relative DSL patterns and not the increasing global-mean contribution. This pattern is due to a slowdown in the Atlantic meridional overturning circulation (AMOC), which is a strong signal in all CESM-LE runs forced by the RCP8.5 scenario [see Fig. 8 in Meehl et al. (2013)]. An AMOC reduction has been a ubiquitous signal in nearly all future climate projections, and is caused by an increase in GHGs. In some CESM runs this leads to a fall in SST just south of Greenland in the near future, although SST begins to increase there later in time as the GHG warming signal gets larger. A discussion of this process in the North Atlantic is in Yeager et al. (2016), and the SST reduction in observations over 2013-16 is analyzed in Josey et al. (2018).

\section{Effects of salinity changes}

So far, only the temperature changes affecting sea level have been discussed. However, there are some regions in Figs. 4, 6, and 8 where the contoured changes in potential density do not reflect temperature changes. The reason is that salinity changes can also be important in affecting potential density, especially where the temperatures are cold and the thermal coefficient of expansion is therefore small. Figure 9 shows the equivalent change in DSL due to salinity and temperature changes as a function of depth if those changes occurred over a depth of $100 \mathrm{~m}$. The figure shows the changes in the global ocean and Atlantic Ocean over the satellite era, 1993-2020, and into the future, 2020-50. Comparison of Figs. 9a and 9c shows that salinity has a smaller effect on DSL than temperature 

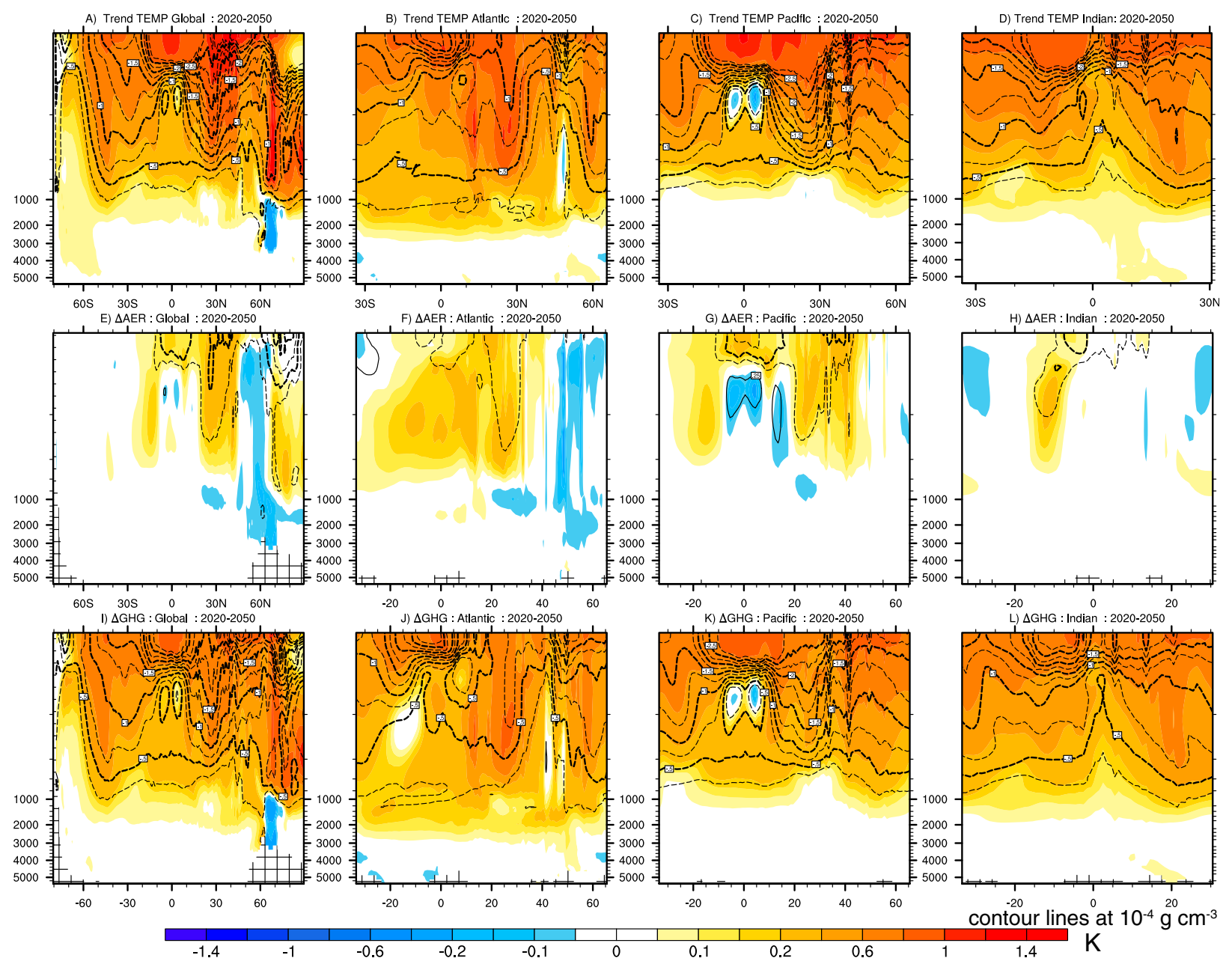

FIG. 8. Temperature (K; colors) and potential density $\left(10^{-4} \mathrm{~g} \mathrm{~cm}^{-3}\right.$; lines at intervals of 0.25$)$ trends from $2020-50$ for (a)-(d) all forcings, (e)-(h) aerosols, and (i)-(l) greenhouse gases. Regions considered include the (a),(e),(i) global ocean and the (b),(f),(j) Atlantic, (c),(g),(k) Pacific, and (d),(h),(l) Indian Ocean basins.

over 1993-2020 in most areas, especially in the tropics, but also in the midlatitudes and the Southern Ocean. The only place where salinity is more important than temperature is in the Arctic, where the DSL budget is driven mainly by freshening (due to melting sea ice), as temperature changes are small. However, a breakdown of this comparison into various ocean basins shows that temperature changes are larger than salinity changes in all ocean basins except the North Atlantic. Figures $9 \mathrm{~b}$ and 9d show that salinity affects DSL as much as temperature in the subtropical North Atlantic. Between $10^{\circ}$ and $40^{\circ} \mathrm{N}$ the DSL fall due to the ocean becoming more saline largely counteracts the DSL rise due to increasing temperature, which is why there is very little net DSL trend in this region in Fig. 5a. This offsetting influence between salinity and thermal effects can be caused by changes in both the ocean gyre and overturning circulations and by changes in the patterns of precipitation minus evaporation. This offsetting in the North Atlantic has been widely reported across climate model projections (e.g., Yin et al. 2010).

Many features of the satellite era continue into the 2020-50 period. Comparison of Figs. 9e and 9g shows that over the global ocean, ocean warming dominates the net DSL budget. The only exception is near the surface in the Arctic Ocean, where DSL rise due to warming is negligible, and freshening increases the DSL due to continuing melting of sea ice and increased precipitation. However, a breakdown into various ocean basins again shows that temperature changes dominate salinity changes in all ocean basins except the North Atlantic. Comparison of Figs. 9f and 9h shows that the DSL change due to increasing salinity in the subtropical North Atlantic offsets much of the DSL increase due to 

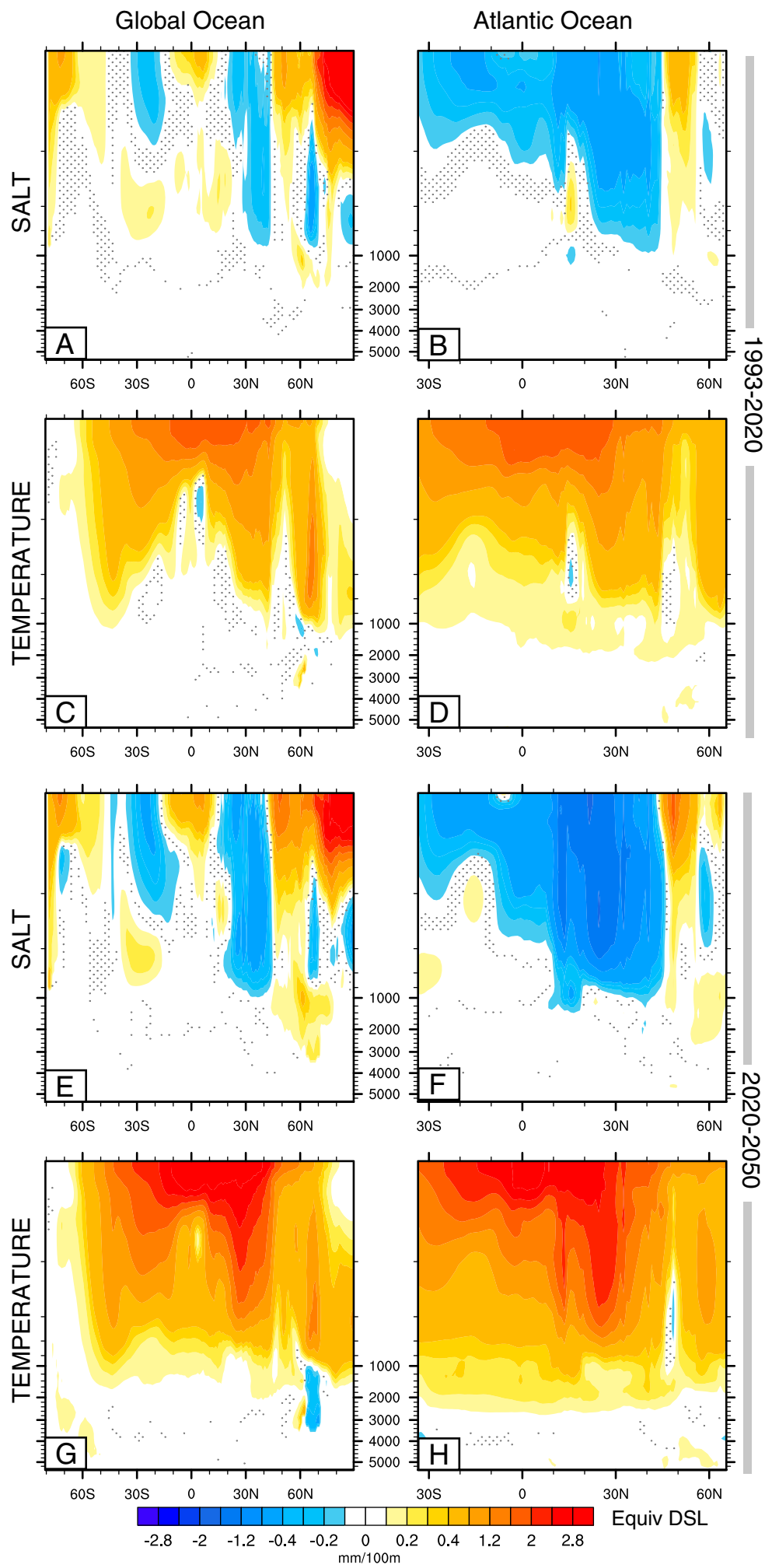

FIG. 9. Zonal-mean equivalent DSL change for contributions from (a),(b),(e),(f) salinity and (c),(d),(g),(h) temperature for the (left) global oceans and (right) Atlantic Ocean as a function of depth and latitude. Contribution to trends for the (a)-(d) 1993-2020 and (e)-(h) 2020-50 periods. 

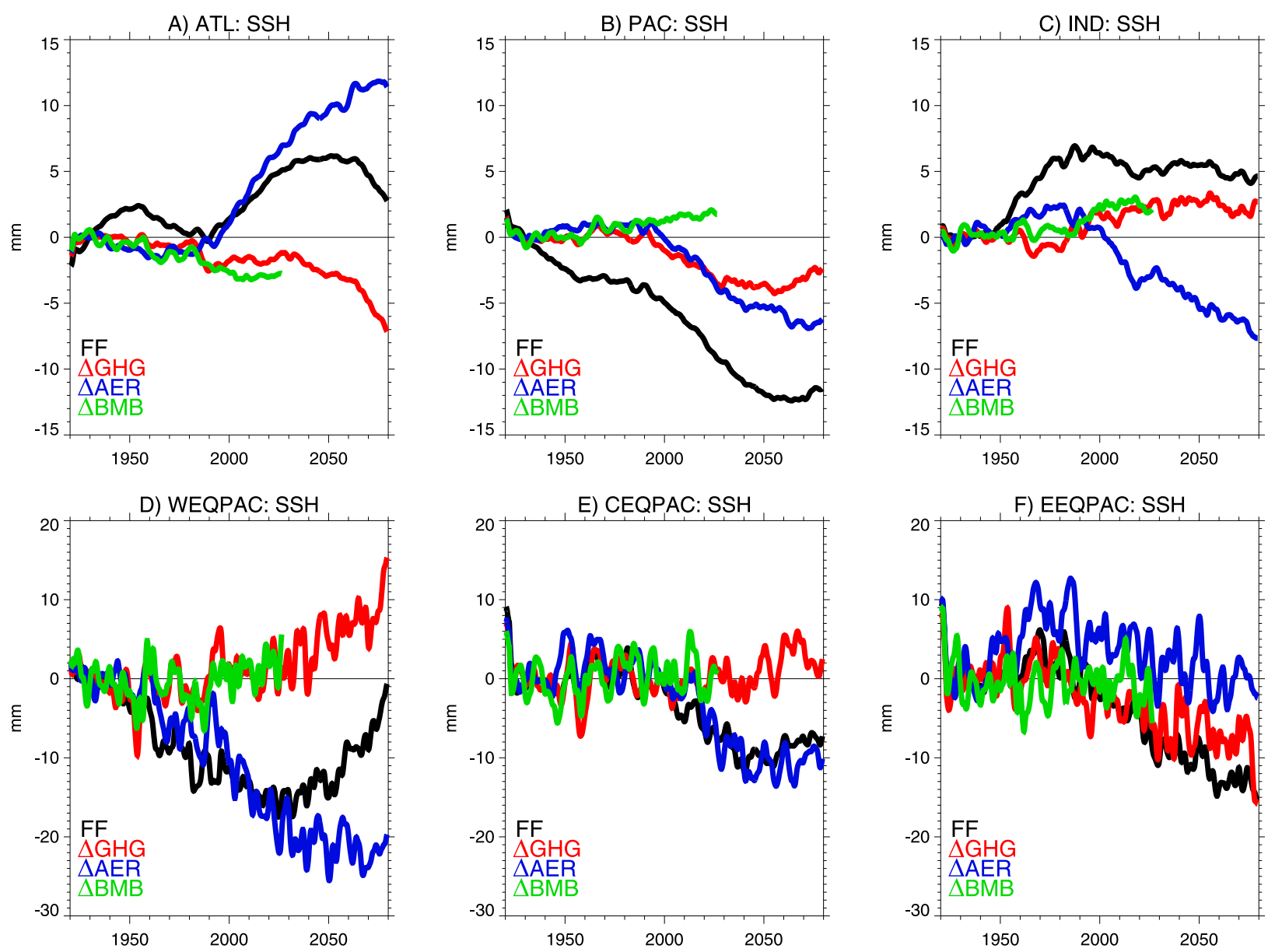

FIG. 10. Time series of DSL anomalies (mm) in the (a) Atlantic, (b) Pacific, (c) Indian, (d) west equatorial Pacific, (e) central equatorial Pacific, and (f) east equatorial Pacific basins for the ensemble mean of full-forcing (FF) and contributions from individual forcings based on differences from FF and all-but-GHG (red), all-but-AER (blue), and all-but-BMB forcings (green). See Fig. 1 for definition of regions.

warming. These competing effects again combine to cause very little net change in DSL in the subtropical North Atlantic, shown in Fig. 7a. The change in salinity in this region is due to changes in both the ocean gyre, and especially the overturning circulations forced by both GHGs and aerosols, and the freshwater flux at the surface.

\section{Interbasin contrasts and mechanisms of change}

While the global-mean DSL in POP is constant, regional contrasts between ocean basins are simulated, reflecting mainly their contrasting rates of heat uptake, ocean dynamics, and seawater expansion coefficient. Figure 10 shows the DSL time series from various ocean basins for the total forcing and the contributions from GHGs, AERs, and BMBs. On basin scales, coherent low-frequency changes in DSL are simulated in CESM and attributable to individual forcing agents. In the
Atlantic (Fig. 10a) these changes are characterized by increases over time, except from 1950 to 2000 and after 2060. Individual contributions to the changes involve all forcings, which together contribute to reductions prior to 1990 , followed by increases arising from AERs after 1990 and persisting reductions due to BMBs and GHGs through 2029 and 2080, respectively. These changes coincide closely with steric contributions through 2050 , although steric reductions arising from GHGs after 2050 are larger than DSL reductions, suggesting a role for dynamics and the weakening of AMOC (Yeager et al. 2016; Josey et al. 2018). In the Pacific, DSL reductions characterize both the twentieth and twenty-first century and include contributions from both AERs and GHGs after 2000 that are slightly offset from BMBs. The absence of a large contribution of AERs, GHGs, or BMBs prior to 2000 suggests a potential role for other forcings (e.g., volcanoes and solar). In the Indian Ocean (Fig. 10c), simulated DSL increases from 1950 to 2000 are evident, 

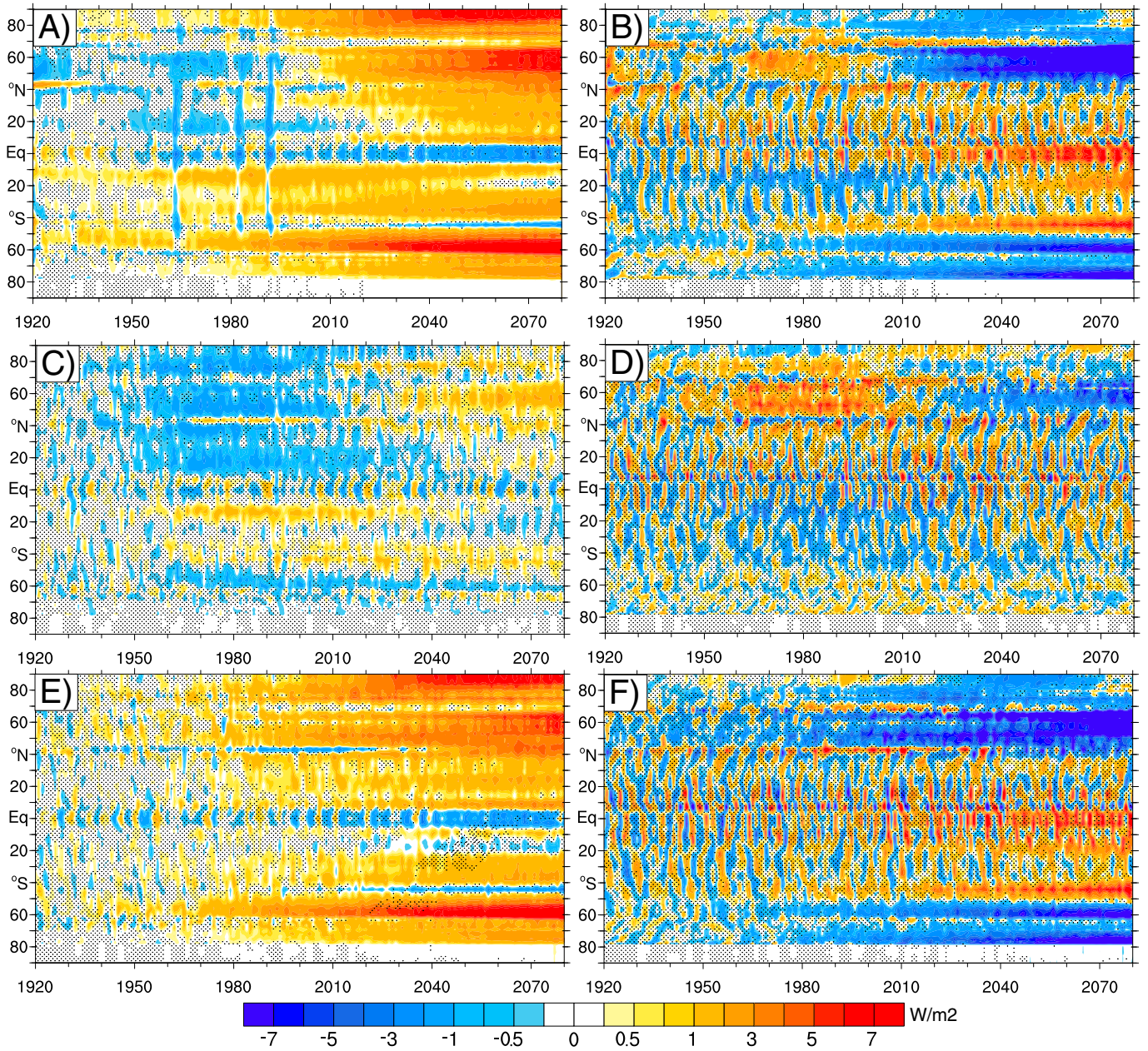

FIG. 11. Zonal-mean evolution of ensemble-mean (left) net downward surface flux and (right) ocean energy divergence anomalies (units: $\mathrm{W} \mathrm{m}^{-2}$ ). Contributions are shown for (a),(b) all forcings, (c),(d) aerosols, and (e),(f) greenhouse gas. Areas where twice the ensemble standard error is greater than the ensemble mean are stippled.

with some contribution from AERs, whereas after 2000 GHGs and BMBs contribute to sustained DSL anomalies, offset significantly by AERs. As for the Pacific, only partial attribution of CESM-LE DSL changes to specific agents can be made, suggesting a role for nonlinear interactions or forcings not considered here. In the equatorial Pacific, in addition to large temporal and zonal variability in DSL associated with ENSO, significant zonal structure in DSL trends and their drivers also exists, with a strong initial reduction and then recovery in the western Pacific Ocean and more monotonic trends in the central and eastern Pacific Ocean. There is also substantial structure in the role of forcings, with AERs playing a key role in the western Pacific Ocean reductions before 2030 that are overcome later in the twenty-first century by GHG influences. In the central Pacific, a mid- to late-twenty-first century reduction is attributable largely to AERs; in the eastern Pacific, latetwentieth-century increases are attributable to AERs but the negative DSL trend in the twenty-first century is attributable to GHGs.

The mechanisms connecting the effects of individual forcings, ocean heat content, and DSL are explored further by examining anomalies in the net downward surface flux over ocean $\left(F_{S}\right)$ and ocean energy convergence $\left(\nabla \cdot \mathbf{F}_{O}\right)$ as shown in Fig. 11. By design, $\nabla \cdot \mathbf{F}_{O}$ is constrained to be zero in the global mean, though $F_{S}$ is not, and is approximately equal to Earth's energy imbalance and ocean heat content tendency. In the CESMLE, the influence of multiple climate forcings on $F_{S}$ (Fig. 11a) is evident, including the cooling effects of major volcanic eruptions in 1963, 1982, and 1991. A broader scale long-term cooling of the $\mathrm{NH}$ is also apparent as is a gradual heating of the ocean in the $\mathrm{SH}$ in the twentieth century and at most latitudes after 2010, with the notable exception of the deep tropics, where $F_{S}$ anomalies remain negative through the late twenty-first century. 
Aerosol forcing (Fig. 11c) plays a strong role in cooling the surface in the NH in the twentieth century but has only a small effect in the $\mathrm{SH}$ and in most of the twentyfirst century. In contrast, the anomalous regional heating of the surface by GHGs (Fig. 11e) becomes significant in the late twentieth century, grows continually through the twenty-first century, and is pervasive in both hemispheres, with an equatorial band of net cooling and transient bands of cooling at $40^{\circ} \mathrm{N}$ and $45^{\circ} \mathrm{S}$ being the main exceptions. Increases in $F_{S}$ in the twenty-first century are largest generally at high latitudes. Simulated $\nabla \cdot \mathbf{F}_{O}$ (Figs. 11b,d,e) exhibits substantial variability, arising mainly from tropical interannual variability, and plays an important role in redistributing the effects of climate forcings on surface forcing into ocean heat content anomalies. In the CESM-LE (Fig. 11b), $\nabla \cdot \mathbf{F}_{O}$ anomalies are broadly characterized by anomalous convergence (i.e., heating) in the NH during the mid-twentieth century and divergence (i.e., cooling) in the $\mathrm{SH}$ subtropics that redistributes $\mathrm{NH}$ net surface cooling anomalies into the SH. During the twenty-first century, the NH north of about $40^{\circ} \mathrm{N}$ transitions to a region of anomalous net divergence, as does the $\mathrm{SH}$ south of $50^{\circ} \mathrm{S}$, transporting positive $F_{S}$ anomalies equatorward, where they converge disproportionately in the SH. Aerosol influences (Fig. 11d) drive much of the NH convergence in the midtwentieth century and are linked to a broad region of SH divergence (as the global total integrates to zero). In the twenty-first century, anomalous divergence at $\mathrm{NH}$ high latitudes $\left(>50^{\circ} \mathrm{N}\right)$ is linked to convergence at lower latitudes, particularly in the SH subtropics. The influence of GHGs (Fig. 11f) again contrasts starkly with that of aerosols. In much of the twentieth century, forced changes are obscured by variability but high-latitude anomalous divergence emerges in the late twentieth century and strengthens into the twenty-first century, transporting heat to lower latitudes where it converges, particularly along the equator and at $45^{\circ} \mathrm{S}$ so as to balance negative anomalies in $F_{S}$ (Fig. 11e), which results in persistent ocean warming at all latitudes (Fig. 8).

\section{Discussion and conclusions}

In total, the analysis presented here demonstrates the existence of a strong FR in sea level trend patterns during the twentieth and twenty-first century driven mainly by GHGs and AERs. The patterns arise from spatially complex changes in ocean heat content, which are in turn driven by both changes in $F_{S}$ and $\nabla \cdot \mathbf{F}_{O}$, and spatial contrasts in the expansion coefficient of seawater. In various eras, the relative influence of the forcing agents has shifted. Over 1950-93, the increase in aerosols generally had a larger impact than increasing
GHGs and in some instances the two tended to offset each other somewhat, as evidenced for example by the vertical structure of ocean warming (Fig. 4). The effect of aerosols is asymmetric across the hemispheres (Fig. 3b), and when not accounted for will likely lead to substantial aliasing in the tide gauge record over 1950 93, which is heavily biased toward the $\mathrm{NH}$ where the DSL trend is reduced by several tens of millimeters in the zonal mean, leading to an underestimate of global sea level if not accounted for and an overestimate of changes through the present day as aerosol effects abate. Over 1993-2020 the effect of decreasing aerosols and increasing GHGs worked in tandem to increase ocean heat content and DSL in some regions such as the Atlantic Ocean, while continuing to offset each other elsewhere (Fig. 6). Such regional effects are central in explaining the regionally contrasting and nonmonotonic DSL changes in basin mean (Fig. 10). Therefore, it is likely that, if aerosol concentrations had not decreased in North America and Europe over the altimeter era, then the magnitude of the region's DSL increase would likely have been smaller than that observed (Fig. 10a). This combination of AER and GHG effects is important for analyzing the altimeter and tide gauge observations over 1993-2020. In the coming decades, this mutual reinforcement of AER and GHG effects becomes widespread, with net warming influences evident in all ocean basins from 2020 to 2050 that will increase the rate of ocean heat uptake dramatically in the coming decades (e.g., Figs. 8a and 11a).

There are some caveats to the results presented in this paper. The first is that the CESM-LE is likely to have biases resulting from its limited $\left(1^{\circ}\right)$ resolution, which does not explicitly resolve ocean eddies, and the physics packages used (Sérazin et al. 2016). Such caveats are underscored by the lack of agreement between observed trends and the CESM-LE forced response in some regions, such as the tropics. Therefore, replication of this analysis across several models would explore what signals are robust across models and what signals are inconsistent. There is an expectation that some aspects, such as the spatial structure of seawater expansivity, will be consistent across models whereas other effects, such as aerosol-cloud interactions and their impact on $F_{S}$, will exhibit model dependence. The second caveat is that the historical record of forcing itself contains significant uncertainties (Lamarque et al. 2010, 2011; Gettelman et al. 2019), which tie directly to $F_{S}$, the uptake of heat into the ocean, and, hence, to DSL. While it is mainly the regional ocean heat uptake distribution that relates to the results presented here, these are strongly tied to the regional distribution of radiative forcing and so also contain some uncertainty. Future 
forcings are more speculative, as irreducible uncertainties exist for both future global emissions and their regional distribution (particularly for AERs and BMBs). Use of RCP8.5 through 2050 is a reasonable business-as-usual scenario, given its similarity to emissions up to the present day, and future regional changes in DSL before 2050 found in this work are similar to those that we find using more moderate forcing scenarios such as RCP4.5 (Sanderson et al. 2018). It is interesting to speculate the effect on DSL if future forcings are not what is in the RCP8.5 scenario. For example, if the aerosols coming from Asia are significantly reduced in the near future, then the North Pacific may show an DSL increase more in line with the North Atlantic compared to the negative trends in DSL shown in Figs. $7 \mathrm{~b}$ and $10 \mathrm{~b}$. In addition, if the rate of GHG increase is significantly smaller than RCP8.5, then the future DSL pattern change may be of smaller amplitude than shown in Fig. 7c.

A final caveat is that the CESM-LE does not include interactive ice sheets. Therefore, the DSL response due to freshwater input from ice loss in Greenland and Antarctica is not included in the results presented here. It has been estimated that, over the last decade, global sea level rise from Greenland and Antarctica melt has been at least as large as that due to increased ocean heat content (Nerem et al. 2018). If ice sheet melt continues to increase strongly in the near future, then this will have a possibly dramatic effect on the DSL projections presented here, through impacts on both ocean circulations and steric effects (Bronselaer et al. 2018). If that occurs, then the future regional patterns of DSL change will be different, and include a substantial contribution from the ice sheet and Earth gravity, rotation, and solidEarth deformation fingerprints that come from ice meltinduced changes in the gravity field and isostatic rebound (Mitrovica et al. 2009; Adhikari et al. 2016; Gregory et al. 2019) combined with the regional pattern shown in Fig. 7c. An interactive Greenland ice sheet has been implemented very recently in the CESM and is currently being tested, but the much more challenging project of an interactive Antarctic ice sheet has not yet been attempted. Future work making use of the approach adopted here using a large ensemble, generated by more comprehensive CESM versions, will further advance our understanding of the multiple interactive aspects of climate change and its sea level-driven impacts in a warming world.

Acknowledgments. We would like to acknowledge the efforts and insights of three anonymous reviewers during the review process. This material is based upon work supported by the National Center for Atmospheric Research, which is a major facility sponsored by the National Science
Foundation under Cooperative Agreement 1852977. The efforts of Dr. Fasullo in this work were partially supported by NASA Award 80NSSC17K0565 and the Regional and Global Model Analysis (RGMA) component of the Earth and Environmental System Modeling Program of the U.S. Department of Energy's Office of Biological and Environmental Research (BER) via National Science Foundation IA 1844590. The efforts of Dr. Fasullo in this work were also supported in part by NSF Award AGS1419571. The authors would like to acknowledge the efforts of Clara Deser, Nan Rosenbloom, Dani Coleman, and Isla Simpson in producing the CESM-SF. All data used in this study are available via the Earth System Grid: https://www.earthsystemgrid.org.

\section{REFERENCES}

Adhikari, S., E. R. Ivins, and E. Larour, 2016: ISSM-SESAW v1.0: Mesh-based computation of gravitationally consistent sealevel and geodetic signatures caused by cryosphere and climate driven mass change. Geosci. Model Dev., 9, 1087-1109, https://doi.org/10.5194/gmd-9-1087-2016.

Aparna, S. G., J. P. McCreary, D. Shankar, and P. N. Vinayachandran, 2012: Signatures of Indian Ocean dipole and El NiñoSouthern Oscillation events in sea level variations in the Bay of Bengal. J. Geophys. Res., 117, C10012, https://doi.org/ 10.1029/2012JC008055.

Armour, K. C., J. Marshall, J. R. Scott A. Donohoe, and E. R. Newsom, 2016: Southern Ocean warming delayed by circumpolar upwelling and equatorward transport. Nat. Geosci., 9, 549-554, https://doi.org/10.1038/ngeo2731.

Bilbao, R. A., J. M. Gregory, and N. Bouttes, 2015: Analysis of the regional pattern of sea level change due to ocean dynamics and density change for 1993-2099 in observations and CMIP5 AOGCMs. Climate Dyn., 45, 2647-2666, https:// doi.org/10.1007/s00382-015-2499-z.

Bromirski, P. D., A. J. Miller, R. E. Flick, and G. Auad, 2011: Dynamical suppression of sea level rise along the Pacific coast of North America: Indications for imminent acceleration. J. Geophys. Res., 116, C07005, https://doi.org/10.1029/2010JC006759.

Bronselaer, B., M. Winton, S. M. Griffies, W. J. Hurlin, K. B. Rodgers, O. V. Sergienko, R. J. Stouffer, and J. L. Russell, 2018: Change in future climate due to Antarctic meltwater. Nature, 564, 53-58, https://doi.org/10.1038/s41586-018-0712-z.

Calafat, F. M., D. P. Chambers, and M. N. Tsimplis, 2013: Interannual to decadal sea-level variability in the coastal zones of the Norwegian and Siberian seas: The role of atmospheric forcing. J. Geophys. Res. Oceans, 118, 1287-1301, https:// doi.org/10.1002/jgrc.20106

Carson, M., A. Köhl, D. Stammer, A. B. A. Slangen, C. A. Katsman, R. S. W. van de Wal, J. Church, and N. White, 2016: Coastal sea level changes, observed and projected during the 20th and 21st century. Climatic Change, 134, 269-281, https:// doi.org/10.1007/s10584-015-1520-1.

Chambers, D. P., C. A. Mehlhaff, T. J. Urban, D. Fujii, and R. S. Nerem, 2002: Low-frequency variations in global mean sea level: 1950-2000. J. Geophys. Res., 107, 3026, https://doi.org/ 10.1029/2001JC001089.

Cummins, P. F., G. S. E. Lagerloef, and G. Mitchum, 2005: A regional index of northeast Pacific variability based on satellite 
altimeter data. Geophys. Res. Lett., 32, L17607, https://doi.org/ 10.1029/2005GL023642.

Deng, J., A. Dai, and H. Xu, 2019: Nonlinear climate responses to increasing $\mathrm{CO}_{2}$ and anthropogenic aerosols simulated by CESM1. J. Climate, 33, 281-301, https://doi.org/10.1175/JCLID-19-0195.1.

Deser, C., and Coauthors, 2020: Isolating the evolving contributions of anthropogenic aerosols and greenhouse gases: A new CESM1 large ensemble community resource. J. Climate, https://doi.org/10.1175/JCLI-D-20-0123.1, in press.

Dieng, H. B., A. Cazenave, B. Meyssignac, O. Henry, K. von Schuckmann, H. Palanisamy, and J. M. Lemoine, 2014: Effect of La Niña on the global mean sea level and North Pacific ocean mass over 2005-2011. J. Geod. Sci., 4, 19-27, https:// doi.org/10.2478/jogs-2014-0003.

Fasullo, J. T., and R. S. Nerem, 2016: Interannual variability in global mean sea level estimated from the CESM large and last millennium ensembles. Water, 8, 491, https://doi.org/10.3390/ w8110491.

— ocean heat content and sea surface height. J. Climate, 30, 9195-9211, https://doi.org/10.1175/JCLI-D-16-0920.1.

—_, and R. S. Nerem, 2018: Altimeter-era emergence of the patterns of forced sea-level rise in climate models and implications for the future. Proc. Natl. Acad. Sci. USA, 115, 12944 12 949, https://doi.org/10.1073/pnas.1813233115.

Gettelman, A. C., and Coauthors, 2019: High climate sensitivity in the Community Earth System Model version 2 (CESM2). Geophys. Res. Lett., 46, 8329-8337, https://doi.org/10.1029/ 2019GL083978.

Gillett, N. P., and K. Von Salzen, 2013: The role of reduced aerosol precursor emissions in driving near-term warming. Environ. Res. Lett., 8, 034008, https://doi.org/10.1088/1748-9326/8/3/ 034008 .

Granier, C., and Coauthors, 2011: Evolution of anthropogenic and biomass burning emissions of air pollutants at global and regional scales during the 1980-2010 period. Climatic Change, 109, 163-190, https://doi.org/10.1007/s10584-011-0154-1.

Gregory, J. M., and Coauthors, 2019: Concepts and terminology for sea level: Mean, variability and change, both local and global. Surv. Geophys., 40, 1251-1289, https://doi.org/10.1007/s10712019-09525-z.

Hamlington, B. D., M. W. Strassburg, R. R. Leben, W. Han, R. S. Nerem, and K. Y. Kim, 2014: Uncovering an anthropogenic sea-level rise signal in the Pacific Ocean. Nat. Climate Change, 4, 782-785, https://doi.org/10.1038/nclimate2307.

- S. H. Cheon, P. R. Thompson, M. A. Merrifield, R. S. Nerem, R. R. Leben, and K. Y. Kim, 2016: An ongoing shift in Pacific Ocean sea level. J. Geophys. Res. Oceans, 121, 5084-5097, https://doi.org/10.1002/2016JC011815.

_ J. T. Fasullo, R. S. Nerem, K. Y. Kim, and F. W. Landerer, 2019: Uncovering the pattern of forced sea level rise in the satellite altimeter record. Geophys. Res. Lett., 46, 4844-4853, https://doi.org/10.1029/2018GL081386.

Han, W., and Coauthors, 2017: Spatial patterns of sea level variability associated with natural internal climate modes. Integrative Study of the Mean Sea Level and Its Components, OEAS Faculty Publications, 221-254, https://doi.org/10.1007/978-3-319-564906_10.

Hauer, M. E., J. M. Evans, and D. R. Mishra, 2016: Millions projected to be at risk from sea-level rise in the continental United States. Nat. Climate Change, 6, 691-695, https:// doi.org/10.1038/nclimate2961.
Hurrell, J. W., M. M. Holland, P. R. Gent, S. Ghan, J. E. Kay, P. J. Kushner, and W. H. Lipscomb, 2013: The Community Earth System Model: A framework for collaborative research. Bull. Amer. Meteor. Soc., 94, 1339-1360, https://doi.org/10.1175/BAMS-D-12-00121.1.

Jones, G. S., S. F. Tett, and P. A. Stott, 2003: Causes of atmospheric temperature change 1960-2000: A combined attribution analysis. Geophys. Res. Lett., 30, 1228, https:// doi.org/10.1029/2002GL016377.

Josey, S. A., J. Hirschi, G. Sinha, A. Duchez, J. P. Grist, and M. Marsh, 2018: The recent Atlantic cold anomaly: Causes, consequences, and related phenomena. Annu. Rev. Mar. Sci., 10, 475-501, https://doi.org/10.1146/annurev-marine-121916-063102.

Kay, J. E., and Coauthors, 2015: The Community Earth System Model (CESM) Large Ensemble project: A community resource for studying climate change in the presence of internal climate variability. Bull. Amer. Meteor. Soc., 96, 1333-1349, https://doi.org/10.1175/BAMS-D-13-00255.1.

Kenigson, J. S., W. Han, B. Rajagopalan, Yanto, and M. Jasinski, 2018: Decadal shift of NAO-linked interannual sea level variability along the U.S. northeast coast. J. Climate, 31, 49814989, https://doi.org/10.1175/JCLI-D-17-0403.1.

Lamarque, J.-F., and Coauthors, 2010: Historical (1850-2000) gridded anthropogenic and biomass burning emissions of reactive gases and aerosols: Methodology and application. Atmos. Chem. Phys., 10, 7017-7039, https://doi.org/10.5194/acp-10-7017-2010.

— , G. P. Kyle, M. Meinshausen, K. Riahi, S. J. Smith, D. P. van Vuuren, A. J. Conley, and F. Vitt, 2011: Global and regional evolution of short-lived radiatively-active gases and aerosols in the representative concentration pathways. Climatic Change, 109, 191-212, https://doi.org/10.1007/s10584-011-0155-0.

Meehl, G. A., and Coauthors, 2013: Climate change projections in CESM1 (CAM5) compared to CCSM4. J. Climate, 26, 62876308, https://doi.org/10.1175/JCLI-D-12-00572.1.

Mitrovica, J. X., N. Gomez, and P. U. Clark, 2009: The sea-level fingerprint of West Antarctic collapse. Science, 323, 753, https://doi.org/10.1126/science.1166510.

Moftakhari, H. R., A. AghaKouchak, B. F. Sanders, D. L. Feldman, W. Sweet, R. A. Matthew, and A. Luke, 2015: Increased nuisance flooding along the coasts of the United States due to sea level rise: Past and future. Geophys. Res. Lett., 42, 9846-9852, https://doi.org/10.1002/2015GL066072.

Nerem, R. S., D. P. Chambers, E. W. Leuliette, G. T. Mitchum, and B. S. Giese, 1999: Variations in global mean sea level associated with the 1997-1998 ENSO event: Implications for measuring long term sea level change. Geophys. Res. Lett., 26, 3005-3008, https://doi.org/10.1029/1999GL002311.

— B. D. Beckley, J. T. Fasullo, B. D. Hamlington, D. Masters, and G. T. Mitchum, 2018: Climate-change-driven accelerated sea-level rise detected in the altimeter era. Proc. Natl. Acad. Sci. USA, 115, 2022-2025, https://doi.org/10.1073/pnas.1717312115.

Neumann, B., A. T. Vafeidis, J. Zimmermann, and R. J. Nicholls, 2015: Future coastal population growth and exposure to sea-level rise and coastal flooding - A global assessment. PLOS ONE, 10, e0118571, https://doi.org/10.1371/journal.pone.0118571.

O'Neill, B. C., E. Kriegler, K. Riahi, K. L. Ebi, S. Hallegatte, T. R. Carter, R. Mathur, and D. P. van Vuuren, 2014: A new scenario framework for climate change research: The concept of shared socioeconomic pathways. Climatic Change, 122, 387400, https://doi.org/10.1007/s10584-013-0905-2.

Peyser, C. E., J. Yin, F. W. Landerer, and J. E. Cole, 2016: Pacific sea level rise patterns and global surface temperature variability. Geophys. Res. Lett., 43, 8662-8669, https://doi.org/ 10.1002/2016GL069401. 
Previdi, M., and L. M. Polvani, 2014: Climate system response to stratospheric ozone depletion and recovery. Quart. J. Roy. Meteor. Soc., 140, 2401-2419, https://doi.org/10.1002/qj.2330.

Rogelj, J., S. Rao, D. L. McCollum, S. Pachauri, Z. Klimont, V. Krey, and K. Riahi, 2014: Air-pollution emission ranges consistent with the representative concentration pathways. Nat. Climate Change, 4, 446-450, https://doi.org/10.1038/nclimate2178.

Sanderson, B. M., K. W. Oleson, W. G. Strand, F. Lehner, and B. C. O'Neill, 2018: A new ensemble of GCM simulations to assess avoided impacts in a climate mitigation scenario. Climatic Change, 146, 303-318, https://doi.org/10.1007/s10584-0151567-z.

Sérazin, G., B. Meyssignac, T. Penduff, L. Terray, B. Barnier, and J.-M. Molines, 2016: Quantifying uncertainties on regional sea level change induced by multidecadal intrinsic oceanic variability. Geophys. Res. Lett., 43, 8151-8159, https://doi.org/ 10.1002/2016GL069273.

Smith, R., and Coauthors, 2010: The Parallel Ocean Program (POP) reference manual: Ocean component of the Community Climate System Model (CCSM) and Community Earth System Model (CESM). Los Alamos National Laboratory Tech. Rep. LAUR01853, $140 \mathrm{pp}$.
Storlazzi, C. D., and Coauthors, 2018: Most atolls will be uninhabitable by the mid-21st century because of sea-level rise exacerbating wave-driven flooding. Sci. $A d v$., 4, eaap9741, https://doi.org/10.1126/sciadv.aap9741.

Stott, P. A., N. P. Gillett, G. C. Hegerl, D. J. Karoly, D. A. Stone, X. Zhang, and F. Zwiers, 2010: Detection and attribution of climate change: A regional perspective. Wiley Interdiscip. Rev.: Climate Change, 1, 192-211, https://doi.org/10.1002/WCC.34.

Yeager, S. G., W. M. Kim, and J. Robson, 2016: What caused the Atlantic cold blob of 2015? US CLIVAR Variations, Vol. 14, No. 2, US CLIVAR Office, Washington, DC, 24-31, https:// usclivar.org/newsletter/newsletters.

Yin, J., S. M. Griffies, and R. J. Stouffer, 2010: Spatial variability of sea level rise in twenty-first century projections. J. Climate, 23, 4585-4607, https://doi.org/10.1175/2010JCLI3533.1.

Zhang, X., and J. A. Church, 2012: Sea level trends, interannual and decadal variability in the Pacific Ocean. Geophys. Res. Lett., 39, L21701, https://doi.org/10.1029/2012GL053240.

Zhao, A., D. S. Stevenson, and M. A. Bollasina, 2019: Climate forcing and response to greenhouse gases, aerosols, and ozone in CESM1. J. Geophys. Res. Atmos., 124, 13876-13894, https://doi.org/10.1029/2019JD030769. 